\title{
A Novel Surfactant Sensitized Fluorescent Sensor for Co(II) Based on Nitrogen Doped Carbon Quantum Dots
}

\author{
Ouwen XU, Wei LIU, Jiawei LI, Shuyu WAN, and Xiashi ZHU* \\ College of Guangling, College of Chemistry \& Chemical Engineering, Yangzhou University, Yangzhou 225002, China
}

*Corresponding author: Xiashi ZHU E-mail: xszhu@yzu.edu.cn, zhuxiashi@sina.com

\begin{abstract}
A novel nitrogen-doped carbon quantum dots (N-CDs) were prepared by the microwave irradiation method. The fluorescence quenching effect of $\mathrm{Co}$ (II) on the $\mathrm{N}$-CDs was studied in the sodium dodecyl sulfate (SDS) medium and the fluorescence quenching was sensitized in the SDS. The linear range of calibration curve for the determination of Co(II) was $0.17 \mu \mathrm{g} / \mathrm{mL}-11.8 \mu \mathrm{g} / \mathrm{mL}$ and the limit of detection was $0.052 \mu \mathrm{g} / \mathrm{mL}$. The method has been applied for the determination of Co(II) in samples with satisfactory results.
\end{abstract}

Keywords: Nitrogen-doped carbon dots; Co(II); sensitized; SDS; fluorescent probe

Citation: Ouwen XU, Wei LIU, Jiawei LI, Shuyu WAN, and Xiashi ZHU, "A Novel Surfactant Sensitized Fluorescent Sensor for Co(II) Based on Nitrogen Doped Carbon Quantum Dots," Photonic Sensors, 2022, 12(2): 152-163.

\section{Introduction}

Cobalt $[\mathrm{Co}(\mathrm{II})]$ is a biologically significant trace element that enters the human body from natural and man-made sources [1]. However, prolonged exposure to high concentrations of cobalt ions and water-soluble cobalt compounds can affect the heart. Cobalt oxides have harmful effects on the lungs and hearts, and may cause cancer in humans [2, 3]. Therefore, it is necessary to establish a sensitive, selective, and accurate method to determine cobalt. Spectroscopy is one of the most common analysis methods for $\mathrm{Co}(\mathrm{II})$, which includes inductively coupled plasma emission spectrometry [4], atomic absorption spectrometry [5], chemiluminescence [6], and molecular fluorescence spectrometry $[7,8]$.

Among various carbon-based materials, carbon dots (CDs) is one of the new materials. Since $\mathrm{Xu}$ et al. [9] accidentally discovered CDs in the process of separating and purifying single-walled carbon nanotubes (SWCNT) in 2004, and CDs have become a research hotspot and applied in multiple fields [10] due to their excellent properties, including good fluorescence characteristics, water solubility, biocompatibility, and low toxicity [11-15]. Like other carbon-based materials, the materials can be modified by element doping $[16,17]$. At present, many studies show that introducing $N$ element to nitrogen-doped carbon dots (N-CDs) preparation can enhance the fluorescence intensity of CDs due to the synergistic charge transfer between electron-rich nitrogen atoms and electron-deficient carbon atoms $[18,19]$.

The main synthesis methods of CDs include the hydrothermal method and microwave method, which belong to the bottom-up synthesis route [20]. The microwave method combines the advantages of the hydrothermal method and has become a very important process. It can provide dense, uniform, and efficient energy for the reaction system, making

Received: 16 June 2021 / Revised: 9 August 2021

(C) The Author(s) 2021. This article is published with open access at Springerlink.com

DOI: $10.1007 / \mathrm{s} 13320-021-0642-5$

Article type: Regular 
the heating of carbon precursors more convenient and fast in the reaction, simplifying the synthesis process, and greatly shortening the synthesis time of CDs. Notably, the influence of microwave on chemical reaction is due to the thermal effect and related to the non-thermal effect of the microwave. The non-thermal effect of microwave also affects the chemical bond through the microwave photon energy. The microwave will not directly cause the change of chemical bond because its photon energy is lower than the energy required to destroy the chemical bond. On the contrary, some chemical bonds break due to the weakening of bond energy in the chemical reaction process and will form new chemical bonds under microwave action [21, 22]. Therefore, the synthesis of CDs by the microwave method has received extensive attention now.

Sensitizers, mainly surfactants, play an essential role in the dispersion of materials and controlling particle morphology. It has been reported that surfactant as a sensitizer can enhance chemiluminescence [23]. The study of fluorescence found that the sensitizing system can maintain a long fluorescence lifetime and strong luminescence intensity [24]. Therefore, the sensitivity of the spectral analysis can be improved by establishing a sensitization system by the sensitizer. In our previous publications, the sensitizing effect of surfactant on the determination of metal ions by ultraviolet-visible spectroscopy (UV-Vis) spectrophotometry and spectrofluorimetric was developed [25, 26]. However, sodium dodecyl sulfate (SDS) sensitized fluorescence quenching method of CDs for the analysis Co(II) seems to be lacking.

In this paper, N-CDs were synthesized by the microwave synthesis method. Co(II) could bring on the fluorescence quenching of N-CDs, and there was a linear relationship between the fluorescence quenching value $(\Delta F)$ and the concentration of $\mathrm{Co}(\mathrm{II})$. A novel SDS sensitized CDs fluorescence quenching method for analysis Co(II) was established.

\section{Experiment}

\subsection{Reagents and instruments}

Glucose, SDS (sodium dodecyl sulfate), $\beta-\mathrm{CD}$ (beta cyclodextrin), $\mathrm{KH}_{2} \mathrm{PO}_{4}$ (disodium hydrogen phosphate), and $\mathrm{Na}_{2} \mathrm{HPO}_{4}$ (potassium dihydrogen phosphate) were purchased from Sinopharm Chemical Reagent Co., Ltd. (Shanghai, China). Ethylenediamine, DTAB (dodecyl trimethyl ammonium bromide), and SDBS (sodium dodecyl benzene sulfonate) were purchased from Shanghai Aladdin Bio-Chem Technology Co., LTD (Shanghai, China). The standard solution of Co(II) and water quality-determination of Co(II) were purchased from Beijing Zhongke Quality Inspection Biotechnology Co., Ltd. (Beijing, China).

SDS solution was prepared by accurately weighing, dissolving, and moving the appropriate amount of SDS into a $100 \mathrm{ml}$ volumetric flask and constant volume with distilled water.

The phosphate buffer solution was prepared by accurately weighing, dissolving, and transferring $\mathrm{KH}_{2} \mathrm{PO}_{4}$ and $\mathrm{Na}_{2} \mathrm{HPO}_{4}$ into two $250 \mathrm{ml}$ volumetric flasks, respectively, using the $\mathrm{pH}$ meter to mix the solution with the $\mathrm{pH}$ value of 3.0-8.0. All the reagents were of analytical reagent grade, and the experimental water was distilled water.

The fluorescence measurements were carried out on an F-7000 fluorescence spectrophotometer (Hitachi, Japan). The UV-Vis absorption spectra were recorded on a Thremo-1780 UV-Vis spectrophotometer (TMO, USA). Fourier transform infrared spectra (FTIR) were recorded on a TENSOR27 FTIR spectrometer (Bruker, Germany). Microwave digestion was carried out in MARS 6240/50 microwave digestion system (CEM, USA).

\subsection{Microwave synthesis of N-CDs}

In this experiment, nitrogen-doped carbon dots (N-CDs) were synthesized by the microwave synthesis method, and the specific steps were as follows (Fig. 1): $0.1 \mathrm{~g}$ glucose and $450 \mu \mathrm{L}$ ethylenediamine were mixed into $10 \mathrm{~mL}$ solution, 
then put into polytetrafluoroethylene tube, and the reaction was carried out under the condition that the reaction temperature increased in $3 \mathrm{~min}$ and kept for $10 \mathrm{~min}$ in a microwave digestion apparatus with microwave power of $450 \mathrm{~W}$. After the reaction was completed, the solution was cooled to room temperature and purified with a dialysis membrane with molecular weight cut-off of $1000 \mathrm{Da}$ for $24 \mathrm{~h}$. At last, the $\mathrm{N}-\mathrm{CDs}$ were stored at $4{ }^{\circ} \mathrm{C}$ for future analysis.

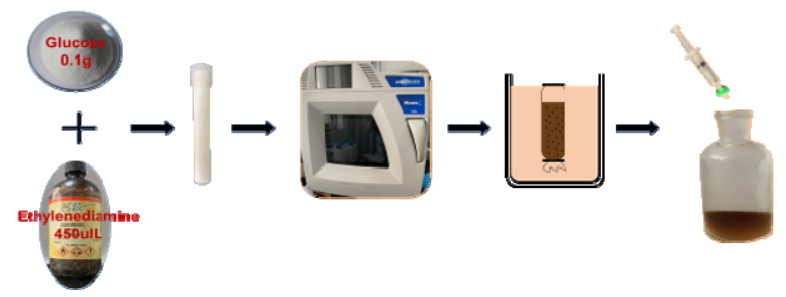

Fig. 1 Preparation diagram of N-CDs.

\subsection{Detection of $\mathrm{Co}(\mathrm{II})$}

The determination solution was prepared by adding a certain amount of $\mathrm{Co}$ (II) solution into an $\mathrm{N}-\mathrm{CDs}$ solution system. The fluorescence spectra were recorded at room temperature with the excitation wavelength of $323 \mathrm{~nm}$ and the emission wavelength of $412 \mathrm{~nm}$.

\subsection{Measurement of fluorescence quantum yield}

Fluorescence quantum yield was generally measured by the reference method. At the same excitation wavelength $(323 \mathrm{~nm})$, the area of the fluorescence spectrum of diluted solutions of sample and reference substance were measured by fluorescence spectrophotometer, respectively. The absorbance of ultraviolet-visible light at the same excitation wavelength was measured. These values were substituted for the formula as follows:

$$
\Phi=\Phi_{s} \frac{F_{u}}{F_{s}} \frac{A_{s}}{A_{u}}
$$

where $F$ represents the fluorescence integral area, $\Phi$ represents the quantum yield, and $A$ represents the absorbance at the excitation wavelength, respectively. The subscript $s$ refers to the quinine sulfate and $u$ refers to the N-CDs.

\section{Results and discussion}

\subsection{Synthesis and characterization of N-CDs}

\subsubsection{Synthesis optimization of $\mathrm{N}-\mathrm{CDs}$}

This experiment investigated the effects of various conditions (the dosage of ethylenediamine, reaction time, and microwave power) on the fluorescence quantum yield $(\Phi)$ of N-CDs.

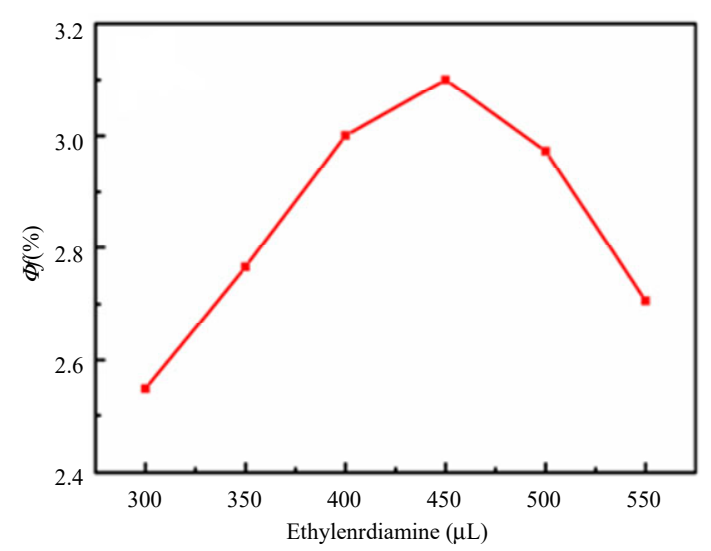

(a)

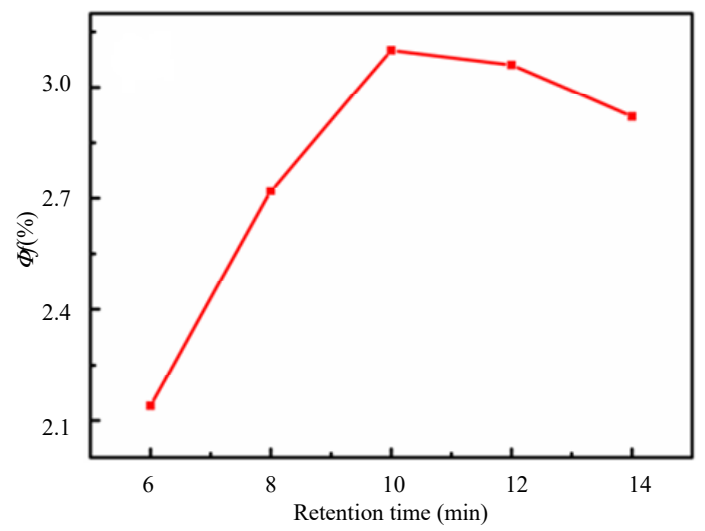

(b)

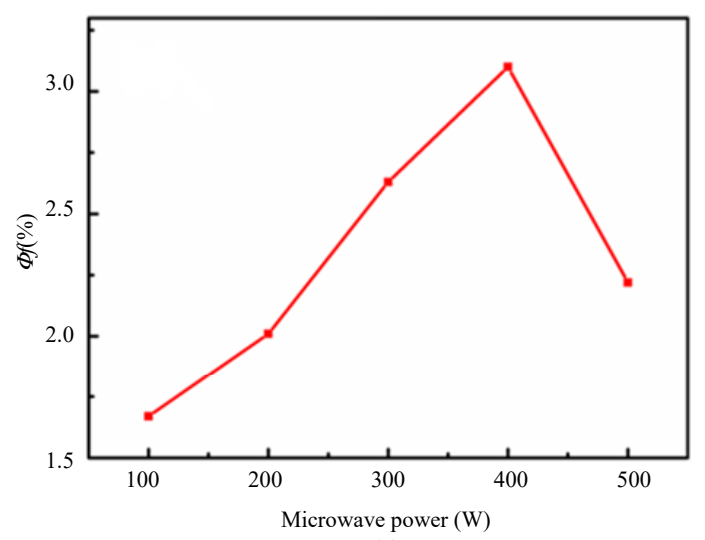

(c)

Fig. 2 Fluorescence quantum yield of N-CDs synthesized at different conditions: (a) the dosage of ethylenediamine, (b) reaction time, and (c) microwave power. 
As shown in Fig. 2(a), the optimum dosage of ethylenediamine was $450 \mu \mathrm{L}$. This phenomenon might be due to the ethylenediamine as a modifier passivating the surface of N-CDs, filling in the vacancy defects on the surface of N-CDs, and making the fluorescence emission more stable. However, the excessive dosage of ethylenediamine might cause the coupling aggregation because the ethylenediamine adhered to the surface of N-CDs and made the $\Phi$ of N-CDs decreased [27].

As shown in Figs. 2(b) and 2(c), when the reaction time was set at $6 \mathrm{~min}-14 \mathrm{~min}$ or the microwave power was set at $100 \mathrm{~W}-500 \mathrm{~W}$, the maximum value of $\Phi$ appeared at $10 \mathrm{~min}$ and $400 \mathrm{~W}$, respectively. The reason might be that the reaction time was too short or the microwave power was too low, which resulted in a decrease in the N-CDs crystal number and insufficient crystal nucleus growth. If the reaction time was too long or the microwave power was too high, N-CDs might easily produce large particles, which would also lead to the uneven particle size of $\mathrm{N}-\mathrm{CDs}$, resulting in a decrease in the $\Phi$ of N-CDs [28].

\subsubsection{Comparison of synthesis methods}

The synthesis of N-CDs by the microwave method was highly similar to that by the hydrothermal method. The microwave method would first provide instantaneous conditions of high temperature and high pressure. Under this condition, glucose first formed organic molecular clusters, and then these organic molecular clusters would gradually form a small number of carbon nuclei due to dehydration and carbonization. With the extension of the reaction time, the carbon nucleus became larger, with many oxygen/nitrogen groups on the surface. Besides, the non-thermal effect of microwaves such as radiation promoted the reaction of cracking, cross-linking, agglomeration, condensation, and carbonization and thus, more NCDs were generated [27].

The properties of N-CDs synthesized by the hydrothermal method $[\mathrm{N}-\mathrm{CDs}(\mathrm{H})]$ and microwave method $[\mathrm{N}-\mathrm{CDs}(\mathrm{M})]$ were compared. As shown in Table 1, the reaction time of $\mathrm{N}-\mathrm{CDs}(\mathrm{H})$ was longer, and the fluorescence quantum yield was higher. However, after sensitized by SDS, the fluorescence quantum yield of $\mathrm{N}-\mathrm{CDs}(\mathrm{H})$ was lower than that of $\mathrm{N}-\mathrm{CDs}(\mathrm{M})$, which might be due to the influence of SDS on the dispersion and particle morphology of $\mathrm{N}-\mathrm{CDs}$ in solution.

The sensitivity of $\mathrm{N}-\mathrm{CDs}(\mathrm{M})$ was better than that of N-CDs(H) $\left[K_{\mathrm{SVN}-\mathrm{CDs}(\mathrm{M})}>K_{\mathrm{SVN}-\mathrm{CD}(\mathrm{H}), \mathrm{LOD}_{\mathrm{N}-\mathrm{Ds}(\mathrm{M})}<}\right.$ $\left.\mathrm{LOD}_{\mathrm{N}-\mathrm{CDs}(\mathrm{H})}\right]$. This phenomenon may be due to the $\mathrm{N}-\mathrm{CDs}$ level synthesized by microwave matching the lowest unoccupied molecular orbital level of Co, which led to higher photon transfer efficiency. In conclusion, N-CDs synthesized by microwave irradiation was more suitable as a fluorescent sensing probe for $\mathrm{Co}(\mathrm{II})$.

Table 1 Comparison of synthetic method.

\begin{tabular}{cccccc}
\hline Methods & Time & $\Phi$ & $\Phi(\mathrm{SDS})$ & $\begin{array}{c}\text { Quenching } \\
\text { constant }\left(K_{\mathrm{SV}}\right)\end{array}$ & $\begin{array}{c}\text { limit of detection } \\
(\mathrm{LOD})\end{array}$ \\
\hline $\begin{array}{c}\text { Microwave } \\
\text { method }\end{array}$ & $45 \mathrm{~min}$ & $3.1 \%$ & $11.2 \%$ & 0.1281 & $52 \mu \mathrm{g} / \mathrm{L}$ \\
$\begin{array}{c}\text { Hydrothermal } \\
\text { method }\end{array}$ & $7 \mathrm{~h}$ & $7.1 \%$ & $8.6 \%$ & 0.0778 & $66 \mu \mathrm{g} / \mathrm{L}$ \\
\hline
\end{tabular}

\subsubsection{Characterization of $\mathrm{N}-\mathrm{CDs}$}

The transmission electron microscope (TEM) image is shown in Fig. 3(a). It could be observed that $\mathrm{N}-\mathrm{CDs}$ were spherical and well distributed. The size distribution of N-CDs was mainly in the range of $2 \mathrm{~nm}-3 \mathrm{~nm}$. The X-ray diffraction (XRD) pattern in Fig. 3(b) shows a broad diffraction peak around $23^{\circ}$, which was consistent with the (002) lattice spacing of carbon-based materials with the turbostratic disorder.

Figure 3(c) shows the ultraviolet absorption spectra of N-CDs (Curve 1), ethylenediamine (Curve 2), and glucose (Curve 3). Compared with Curves 2 and 3, Curve 1 exhibited an absorption peak of $n-\pi$ transition at $280 \mathrm{~nm}$, which indicated the formation of $\mathrm{C}=\mathrm{O}$ or $\mathrm{C}=\mathrm{N}$.

The infrared spectra of glucose (Curve 1), ethylenediamine (Curve 2), and N-CDs (Curve 3) are shown in Fig. 3(d). There were new peaks at 
$1369 \mathrm{~cm}^{-1}$ and $1660 \mathrm{~cm}^{-1}$ in Curve 3, corresponding to the stretching vibration peak of $\mathrm{C}-\mathrm{N}$ and $\mathrm{C}=\mathrm{O}$ or $\mathrm{C}=\mathrm{N}$, which was consistent with the peak of nitrogenous functional groups in Curve 2. This result indicated the formation of carbon quantum dots, and $\mathrm{N}$ was successfully doped into carbon quantum dots. The peak at $2960 \mathrm{~cm}^{-1}$ was attributed to the stretching vibration $-\mathrm{H}$ structure. The peak at

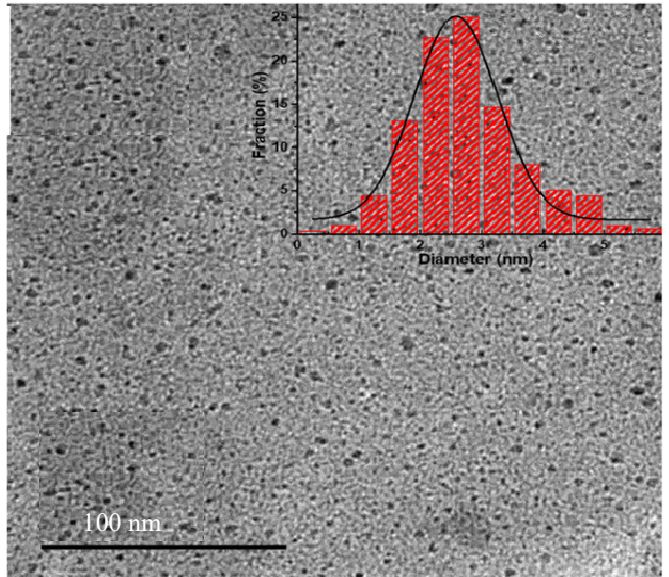

(a)

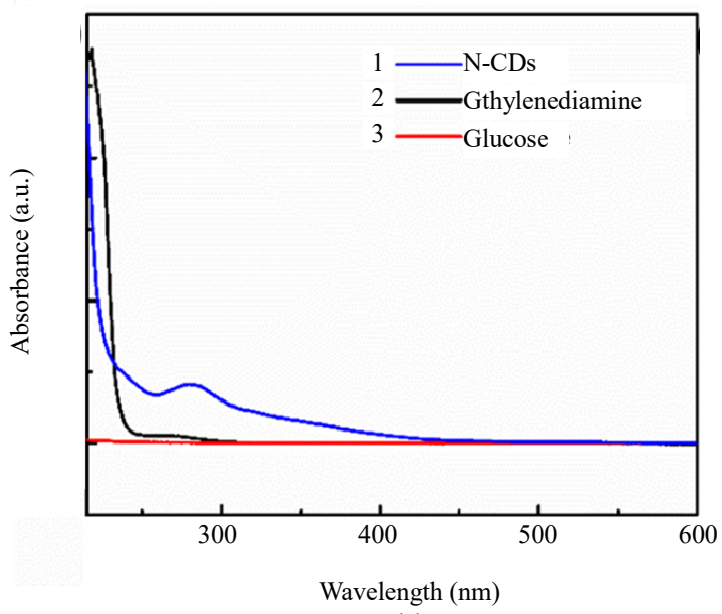

(c)
$3396 \mathrm{~cm}^{-1}$ was assigned to the stretching vibration of $-\mathrm{OH}$ and $-\mathrm{NH}$.

In summary, the above could prove the formation of N-CDs. The surface of N-CDs was rich in hydrophilic groups, such as hydroxyl groups, carboxyl groups, and amino groups, which made NCDs have good water solubility and stability.

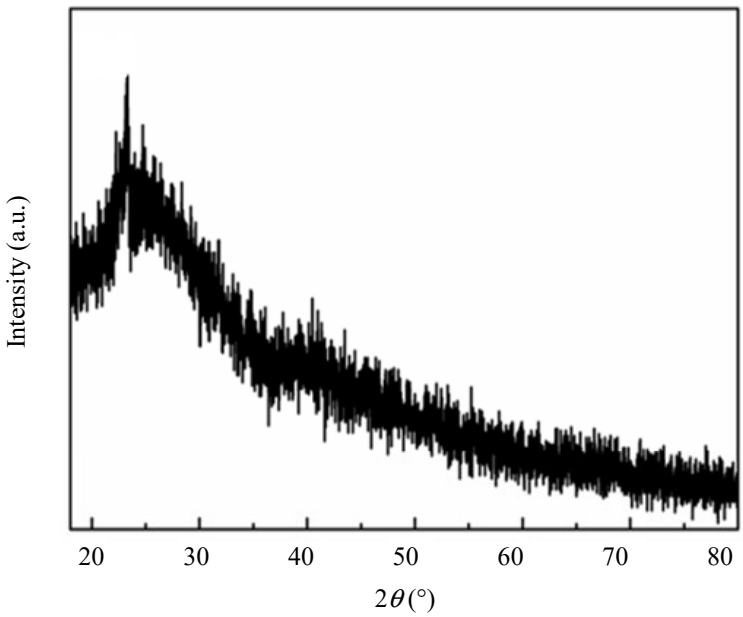

(b)

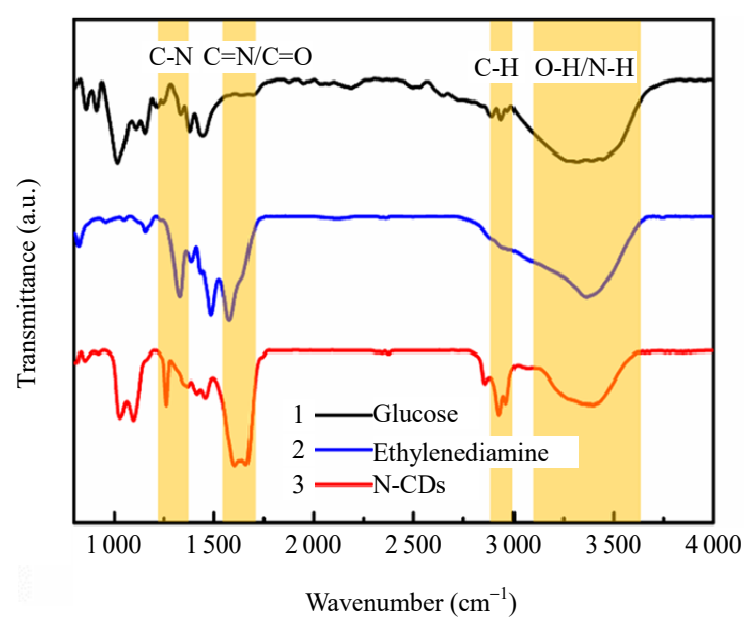

(d)

Fig. 3 Characterization of N-CDs: (a) TEM image of N-CDs (inset: the histogram of the size distribution for N-CDs), (b) XRD of N-CDs, ethylenediamine, and glucose, (c) UV-Vis spectrum of N-CDs, and (d) FTIR spectrum of N-CDs, ethylenediamine and glucose.

\subsubsection{Fluorescent properties of N-CDs}

Figure4(a) describes the fluorescence spectra of the N-CDs solution at different excitation wavelengths. When the excitation wavelength was changed from $280 \mathrm{~nm}$ to $350 \mathrm{~nm}$, the emission wavelength shifted with the shift of excitation wavelength, and the fluorescence intensity increased first and then decreased. The fluorescence intensity was the highest till the excitation wavelength located at $323 \mathrm{~nm}$ [Fig. 4(b)] and showed blue light [Fig. 4(c)]. 


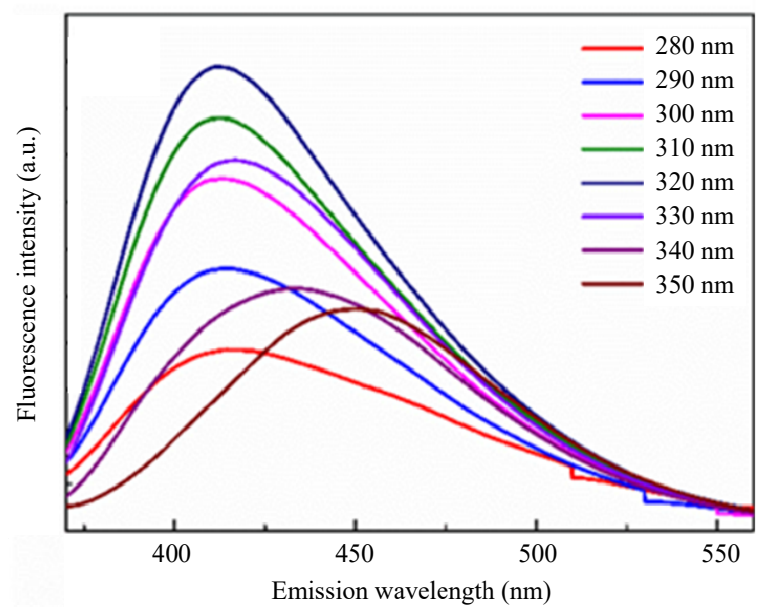

(a)

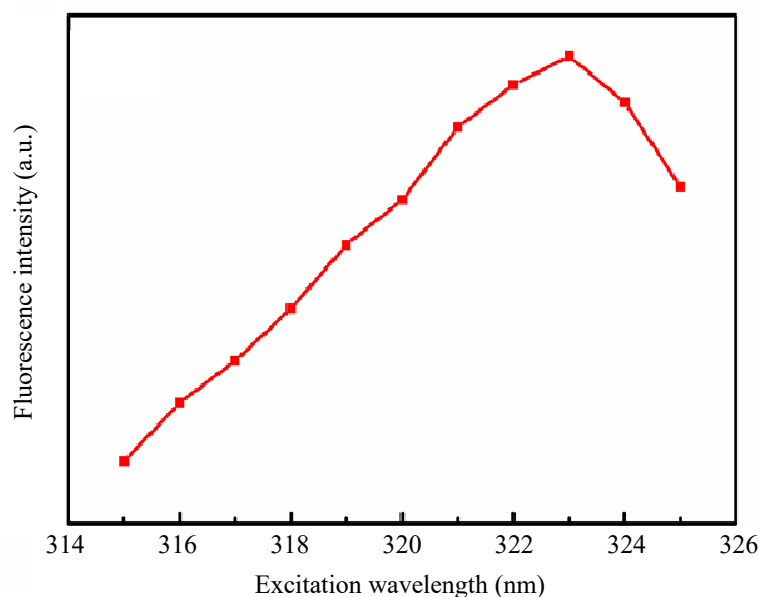

(b)

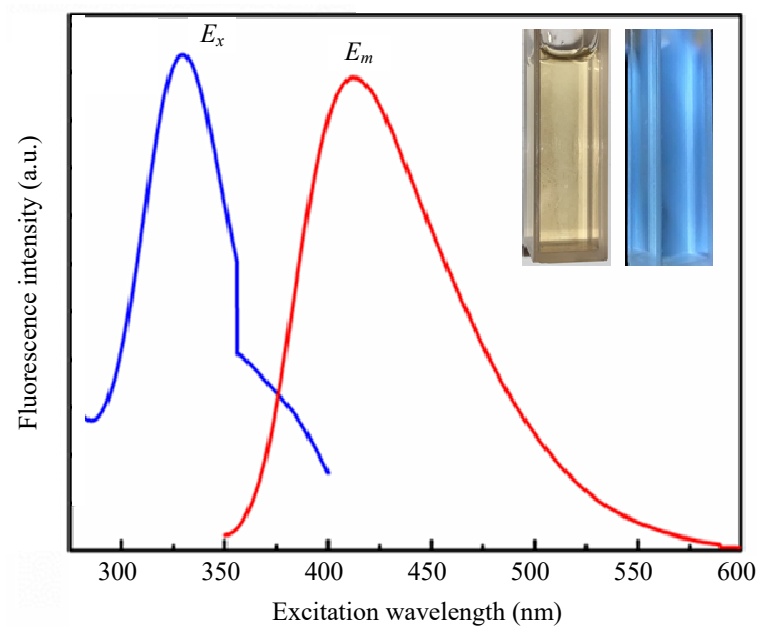

(c)

Fig. 4 Fluorescent properties of N-CDs: (a) fluorescence emission spectra of N-CDs at different excitation wavelengths from $280 \mathrm{~nm}$ to $350 \mathrm{~nm}$, (b) fluorescence intensity of N-CDs at $315 \mathrm{~nm}-325 \mathrm{~nm}$, and (c) optimum excitation wavelength and optimum emission wavelength of N-CDs (inset: fluorescence of $\mathrm{N}-\mathrm{CDs}$ solution at excitation wavelength).

\subsection{Detection of Co(II)}

\subsubsection{Fluorescence quenching and sensitization}

Figure 5(a) was obtained by adding Co(II) into the N-CDs system and scanning the solution at $323 \mathrm{~nm}$ excitation wavelength. Curves from the top to the bottom were fluorescence spectra of N-CDs with different $\mathrm{Co}$ (II) concentrations added. It could be observed that with an increase in $\mathrm{Co}$ (II) concentration in the N-CDs system, the fluorescence intensity of $F_{\mathrm{N}-\mathrm{CDs}}$ decreased. This result revealed that $\mathrm{Co}$ (II) had a quenching effect on N-CDs which could "turn off" the fluorescence signal.

The experiment investigated the effects of different sensitizers [DTAB, SDBS, $\beta-C D$, SDS, TX-100, and amino acid ionic liquids (AAIL)] on the fluorescence quenching system of $\mathrm{Co}(\mathrm{II})-\mathrm{N}-\mathrm{CDs}$. As shown in Fig. 5(b), SDS was the most effective sensitizer to improve the detection sensitivity of Co(II) by N-CDs.

In the presence/absence of SDS, the fluorescence spectra of $\mathrm{Co}$ (II)-N-CDs are shown in Fig. 5(c). It could be observed that: (1) the existence of SDS did not affect the emission position of N-CDs; (2) the fluorescence intensity of N-CDs increased significantly with the SDS, which might be due to the formation of micelles by SDS, resulting in the change of solution microenvironment [26]; (3) the quenching effect of the same concentration of $\mathrm{Co}(\mathrm{II})$ on N-CDs was significantly improved $\left(\Delta F_{1}>\Delta F_{2}\right)$ in the presence of SDS. As shown in Fig. 5(d), $\Delta F$ had the maximum value when $2 \%$ SDS was added. Thus, the SDS concentration was determined to be $2 \%$ in this experiment.

\subsubsection{Optimization of conditions}

(1) $\mathrm{pH}$

As shown in Fig. $6, \Delta F$ increased with an increase in $\mathrm{pH}$ at first and then decreased gradually when $\mathrm{pH}>6.0$. The reason may be that in an acidic environment, with an increase in $\mathrm{pH}$ values, the interaction between N-CDs and Co(II) became 


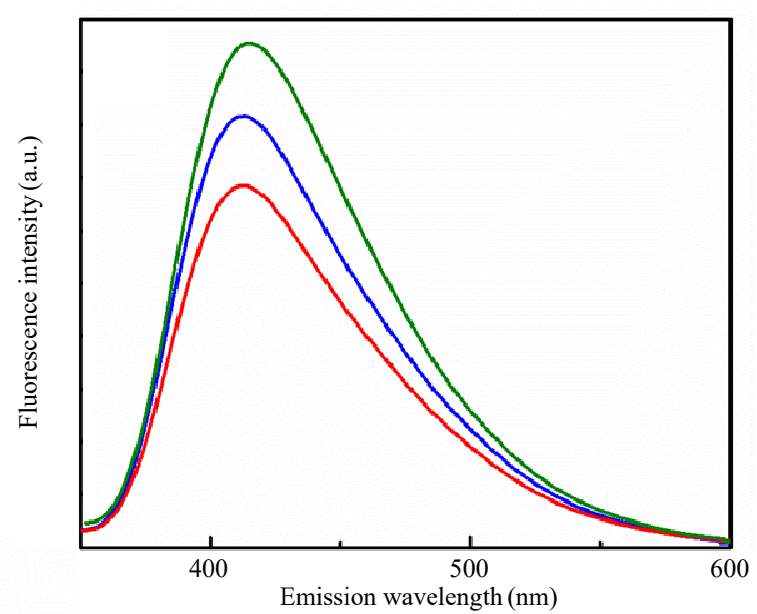

(a)

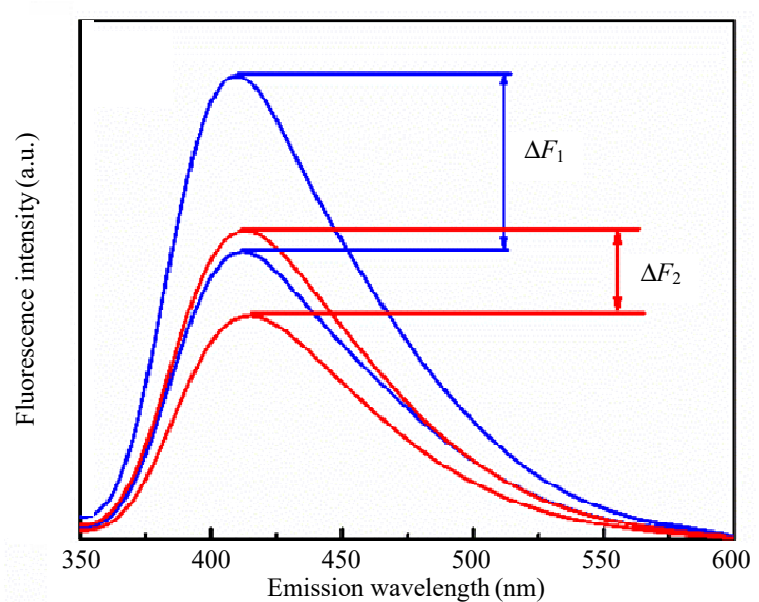

(c)

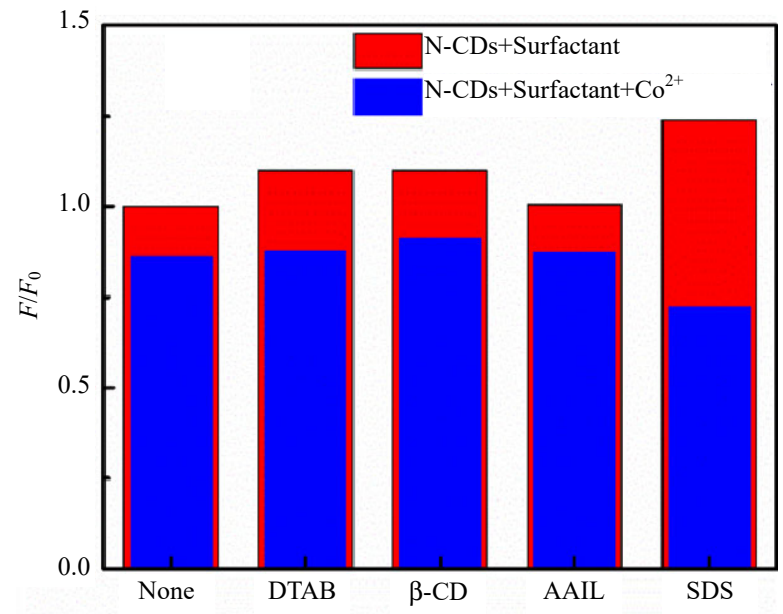

(b)

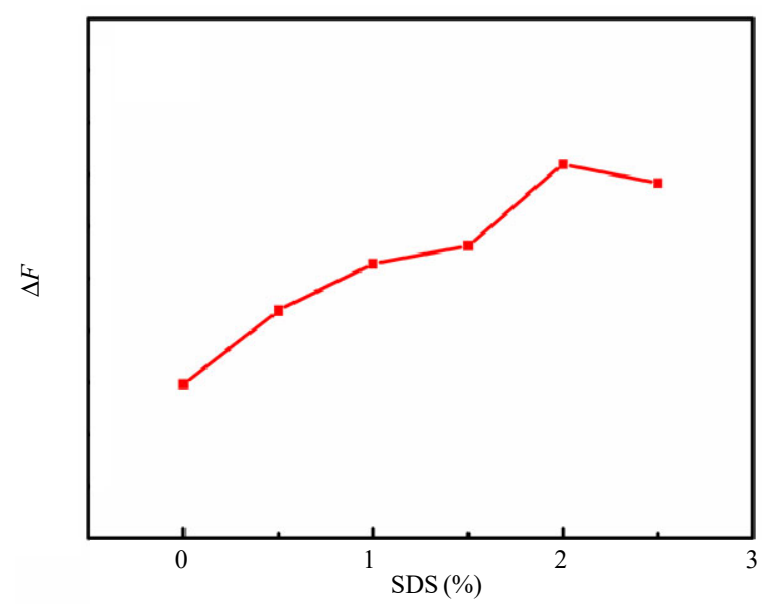

(d)

Fig. 5 Fluorescence quenching and sensitization of N-CDs in detection of Co(II): (a) fluorescence emission spectra of N-CDs solution with different concentrations of $\mathrm{Co}(\mathrm{II})$, (b) fluorescence changes of N-CDs after adding Co(II) under different sensitizers, (c) fluorescence spectra of N-CDs solution before and after SDS added, and (d) fluorescence changed of N-CDs solution in different concentrations of SDS.

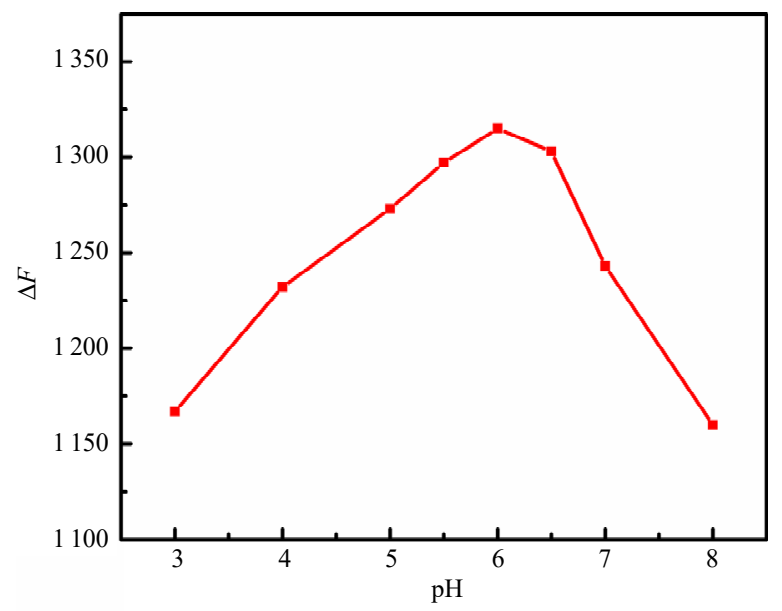

Fig. 6 Fluorescence quenching values $(\Delta F)$ of the N-CDs solution at different $\mathrm{pH}$ stronger where the degree of deprotonation of $\mathrm{N}$ and $\mathrm{O}$ atoms on the surface of N-CDs increased [29]. The hydroxyl side reaction coefficient of Co(II) increased when the $\mathrm{pH}$ was more than 6.0. As a result, the interaction between $\mathrm{Co}(\mathrm{II})$ and $\mathrm{N}-\mathrm{CDs}$ became weaker and $\Delta F$ decreased [30]. Thus, $\mathrm{pH} 6.0$ was picked as the optimal experimental condition for all detection.

\section{(2) Temperature}

$\Delta F$ of the quenching system at temperatures of $10^{\circ} \mathrm{C}-60^{\circ} \mathrm{C}$ was investigated. As shown in Fig. $7, \Delta F$ decreased with an increase in temperature, which could be attributed to the obstruction of the 
formation of ground state complexes at high temperature [31]. In consequence, room temperature $\left(20^{\circ} \mathrm{C}\right)$ was chosen for the convenience of operation.

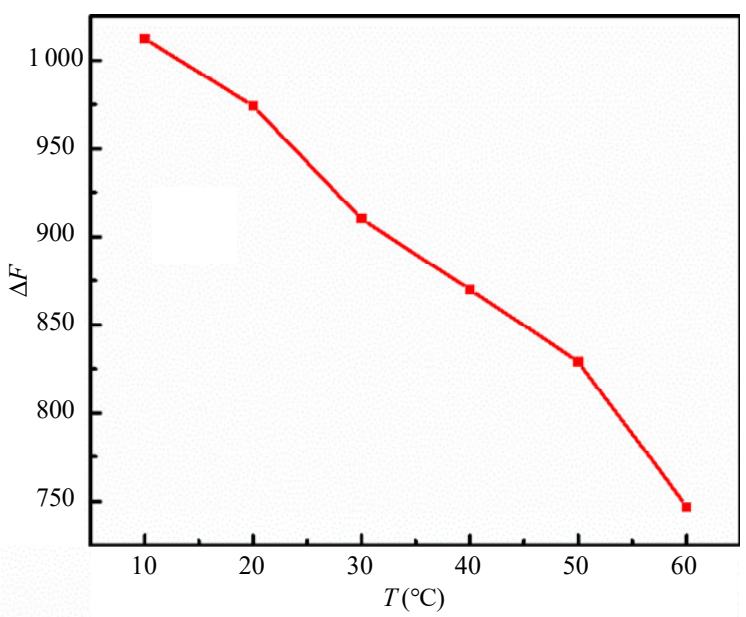

Fig. 7 Fluorescence quenching values $(\Delta F)$ of the N-CDs solution at different temperatures.

(3) Ionic strength

In this experiment, $1.0 \mathrm{~mL} 0 \%-5 \% \mathrm{NaCl}$ were added into the quenching system solution to explore the effect of ionic strength. The results showed that the ionic strength had no effect on $\Delta F$.

\subsubsection{Selective and anti-interference capability}

In order to verify the selectivity of this method, the effects of different metal ions on the quenching of Co(II)-N-CDs-SDS were investigated. As shown in Fig. 8(a), when different metal ions $\left(\mathrm{K}^{+}, \mathrm{Na}^{+}, \mathrm{Ca}^{2+}\right.$, $\mathrm{Cu}^{2+}, \mathrm{Pb}^{2+}, \mathrm{Ni}^{2+}, \mathrm{Al}^{3+}, \mathrm{Fe}^{3+}, \mathrm{Mg}^{2+} c_{\mathrm{M}}=11.8 \mu \mathrm{g} / \mathrm{mL}$, and $c_{\mathrm{Co}}=1.18 \mu \mathrm{g} / \mathrm{mL}$ ) were added into the N-CDsSDS solution, only Co(II) had a significant effect on the fluorescence intensity, while the other metals had no interference on the system. In addition, as shown in Fig. 8(b), $\mathrm{K}^{+}, \mathrm{Na}^{+}, \mathrm{Ca}^{2+}, \mathrm{Cu}^{2+}, \mathrm{Pb}^{2+}, \mathrm{Ni}^{2+}$, $\mathrm{Al}^{3+}, \mathrm{Fe}^{3+}$, and $\mathrm{Mg}^{2+}$ with 10 times the concentration of Co(II) were added to the system, respectively, which could be observed that metal ions hardly had effect on the determination of $\mathrm{Co}(\mathrm{II})$. These results indicated that N-CDs-SDS had a high selectivity for $\mathrm{Co}(\mathrm{II})$ and anti-interference capability.

\subsubsection{Analytical performance}

The linear relationship between $F_{0} / F-1$ and
Co(II) concentration was shown in Fig. 9. The linear equation was $F_{0} / F-1=0.1281 c-0.1023\left(R^{2}=0.9984\right)$ in the range of $0.17 \mu \mathrm{g} / \mathrm{mL}-11.8 \mu \mathrm{g} / \mathrm{mL}$, where $F$ and $F_{0}$ represent the fluorescence intensity of N-CDs in the presence and absence of Co(II), respectively, and $c$ represents the concentration of $\mathrm{Co}$ (II). The limit of detection was $0.052 \mu \mathrm{g} / \mathrm{mL}$ conforming to $3 \sigma / k$, which meant three times of the standard deviation of blank signals were divided by the slope of the calibration curve.

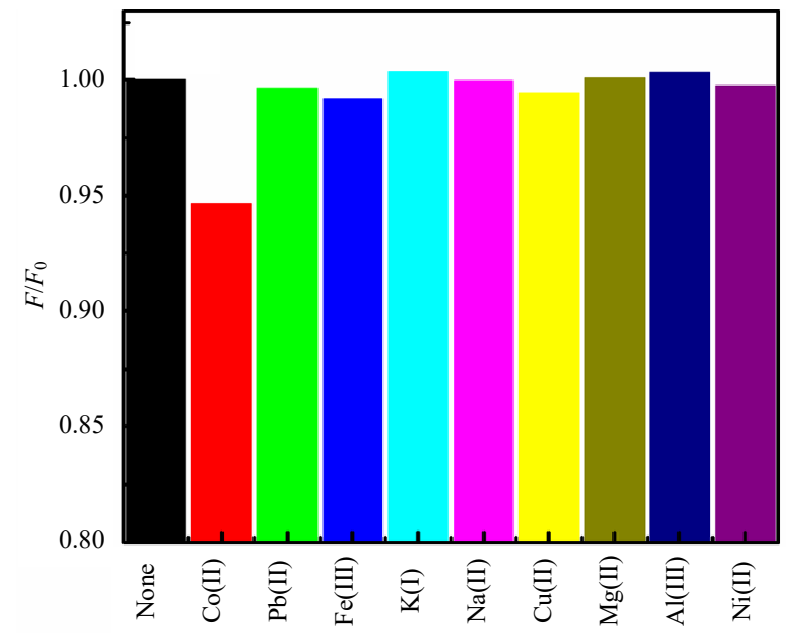

(a)

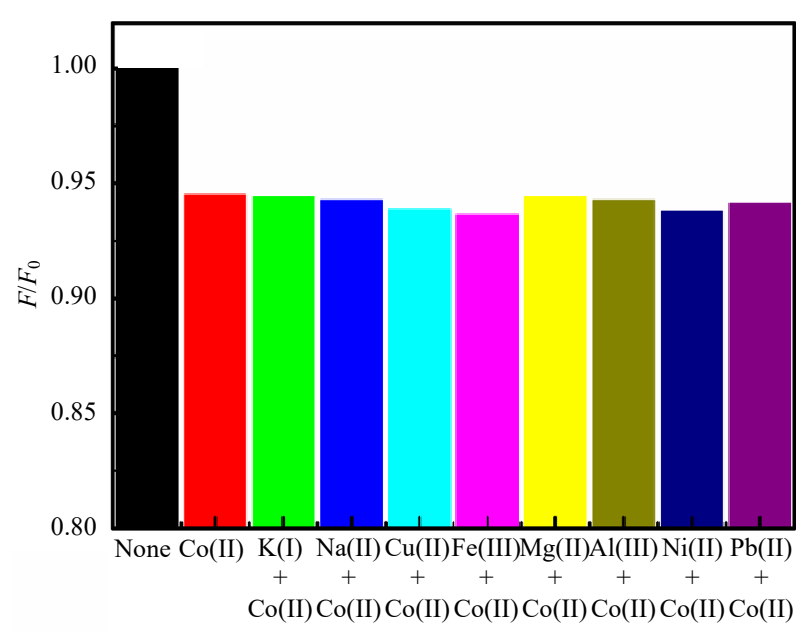

(b)

Fig. 8 Selectivity and anti-interference capability of the method: (a) quenching effect of different metal ions on fluorescence and (b) effect of different metal ions on the fluorescence quenching by $\mathrm{Co}(\mathrm{II})$.

As shown in Table 2, this method had high sensitivity and good linear range compared with other methods. 


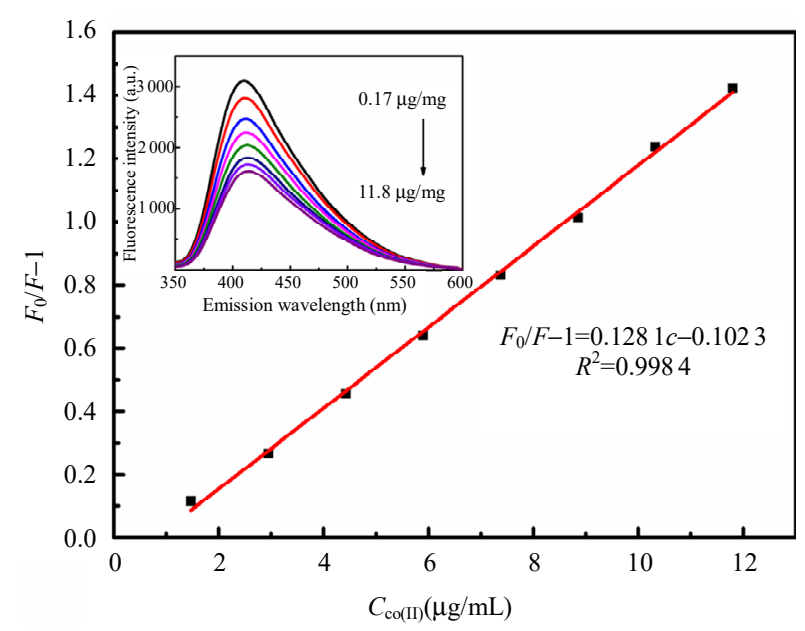

Fig. 9 Linear relationship between fluorescence intensity of the N-CDs solution and different $\mathrm{Co}(\mathrm{II})$ concentrations.

Table 2 Comparison of detection methods.

\begin{tabular}{cccc}
\hline Method & LOD $(\mu \mathrm{g} / \mathrm{mL})$ & Linear range $(\mu \mathrm{g} / \mathrm{mL})$ & Ref. \\
\hline CDs & 0.030 & $0.30-4.70$ & {$[32]$} \\
Ag NPS & 0.410 & $0.10-28.00$ & {$[33]$} \\
N-CDs & 0.023 & $0.056-11.200$ & {$[34]$} \\
N-CDs/SDS & 0.052 & $0.17-11.80$ & This method \\
\hline
\end{tabular}

\subsubsection{Detection of Co(II) in water samples}

(1) Standard water sample

The standard water sample was determined under the optimum conditions (room temperature: $20^{\circ} \mathrm{C}$; buffer solution, $\left.\mathrm{pH}=6 ; 2 \% \mathrm{SDS}\right)$. The result was consistent with the standard values (Table 3, $95 \%$ confidence, $n=3$ ).

Table 3 Detection of Co(II) in standard water sample.

\begin{tabular}{ccc}
\hline Sample & $\begin{array}{c}\text { Standard value } \\
(\mu \mathrm{g} / \mathrm{mL})\end{array}$ & $\begin{array}{c}\text { Determination value } \\
(\mu \mathrm{g} / \mathrm{mL})\end{array}$ \\
\hline $\begin{array}{c}\text { Standard water sample } \\
(\mathrm{GB} / \mathrm{T} 15000)\end{array}$ & 0.0633 & 0.0645 \\
\hline
\end{tabular}

(2) Standard water sample

According to the experimental method, tap water was taken in the laboratory, and 1-mL-tap water was added to the solution system. Then the standard addition method was used to detect the concentration of $\mathrm{Co}$ (II) in tap water. The results in Table 4 showed that the method had a good linearity and the recovery was $94.1 \%-98.0 \%$.
Table 4 Detection of Co(II) in real water sample.

\begin{tabular}{cccc}
\hline & Added $(\mu \mathrm{g} / \mathrm{mL})$ & Found $(\mu \mathrm{g} / \mathrm{mL})$ & Recovery $(\%)$ \\
\hline \multirow{4}{*}{ Tap water } & 0 & - & - \\
& 2.95 & 2.89 & 98.0 \\
& 5.90 & 5.61 & 95.1 \\
& 8.85 & 8.32 & 94.1 \\
& 11.80 & 11.51 & 97.5 \\
\hline
\end{tabular}

\subsection{Discussion on the mechanism}

\subsubsection{Fluorescence quenching mechanism}

Fluorescence quenching can be divided into static quenching and dynamic quenching. Static quenching refers to the interaction between the fluorescence system and quencher to form a ground state complex without fluorescence. Dynamic quenching refers to the fluorescence system returning to the ground state by the energy transfer mechanism or charge transfer mechanism through the collision between the quencher and the fluorescence probe in the excited state. Thermodynamic parameters and UV spectra may explain the quenching mechanism.

(1) Thermodynamic parameters

The results of fitting the linear equation $K_{\mathrm{SV}}$ at $20^{\circ} \mathrm{C}, 40^{\circ} \mathrm{C}$, and $60^{\circ} \mathrm{C}$ were $0.799,0.742$, and 0.739 , respectively, which indicated that the fluorescence quenching constant decreasing with an increase in temperature conformed to the characteristics of static quenching. Therefore, it could be preliminarily judged that the quenching process of N-CDs-SDS fluorescence by $\mathrm{Co}$ (II) was static. That was, the nonfluorescent ground state complexes might be formed during the quenching process [35].

The non-fluorescent ground state complexes were formed by the interaction between receptor molecules and fluorescent molecules. The interaction forces among molecules included hydrogen bond, hydrophobic force, electrostatic force, and van der Waals force. Through further calculation and analysis, thermodynamic parameters $\Delta H^{\Theta}$ (enthalpy change) and $\Delta S^{\Theta}$ (entropy change) could be obtained, thus the molecular interaction in quenching process could be explored. The formula is as follows: 


$$
\ln K=-\frac{\Delta H^{\Theta}}{R T}+\frac{\Delta S^{\Theta}}{R}
$$

where $K$ represents the slope of temperature quenching, $T$ represents the corresponding temperature, and $R$ represents the gas constant.

The results showed that under these temperatures, $\Delta H^{\Theta}$ and $\Delta S^{\Theta}$ were $-1611 \mathrm{~J} / \mathrm{mol}$ and $7.45 \mathrm{~J} / \mathrm{mol}$, respectively. Therefore, it can be ascertained that the static quenching process between $\mathrm{N}$-CDs and $\mathrm{Co}(\mathrm{II})$ was mainly caused by charge interaction [36].

(2) UV spectra

In this experiment, the UV spectra of the NCDs-SDS system and the system added with Co(II) and other metal ions respectively were shown in Fig. 10(a). It could be observed that a new absorption peak appeared at $350 \mathrm{~nm}$ after $\mathrm{Co}$ (II) was added, which was mainly caused by the $n \rightarrow \pi^{*}$ transition of $\mathrm{C}=\mathrm{O}$ or $\mathrm{C}=\mathrm{N}$. This indicated that the formation of ground state complex was consistent with the static quenching conclusion of the quenching process thermodynamics.

The formation of non-fluorescent ground state complexes may be attributed to $\mathrm{Co}(\mathrm{II})$ providing empty orbits as a central ion and forming nonluminescent complexes with $\mathrm{N}-\mathrm{CDs}$. At the same time, $\mathrm{Co}(\mathrm{II})$ with $\mathrm{C}=\mathrm{O}$ and $\mathrm{C}-\mathrm{H}$ formed nonluminescent complexes on the surface of N-CDs, which resulted in a decrease in the fluorescence intensity of the system.

\subsubsection{Sensitization mechanism of SDS}

Fluorescence quantum yield was one of the basic and important parameters of fluorescent materials [36]. It represented the ability of absorption energy to be converted into fluorescence. When the solution was in the SDS medium, the fluorescence quantum yield was $11.2 \%$, much higher than $3.1 \%$ in the water medium. This phenomenon may be due to the self-assembly of SDS in an aqueous solution to form micelles that changed the medium microenvironment and increased the number of photons returning to the ground state by photon radiation. Besides, the presence of SDS could effectively prevent the agglomeration of $\mathrm{N}-\mathrm{CDs}$ and reduced its self-quenching [37]. At the same time, the micelle environment of SDS increased the stability of $\mathrm{Co}(\mathrm{II})-\mathrm{N}-\mathrm{CDs}$ complex, thus increasing $\Delta F$ [Fig. 10(b)]. Therefore, SDS has a sensitizing effect on $\mathrm{N}$ CDs and $\Delta F$ of the CDs-Co(II) system.

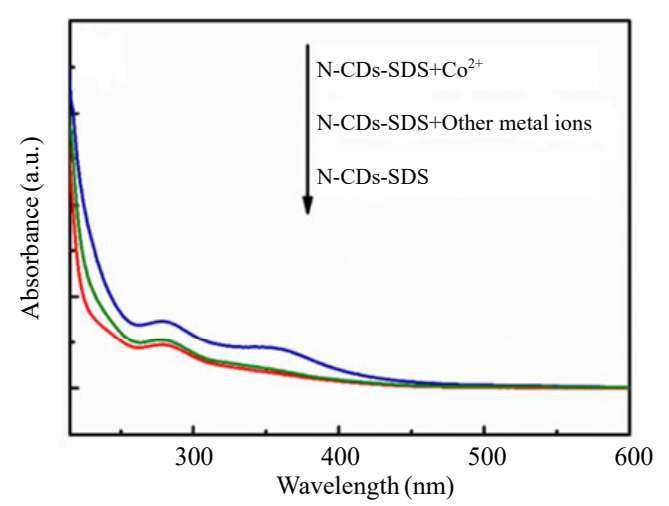

(a)

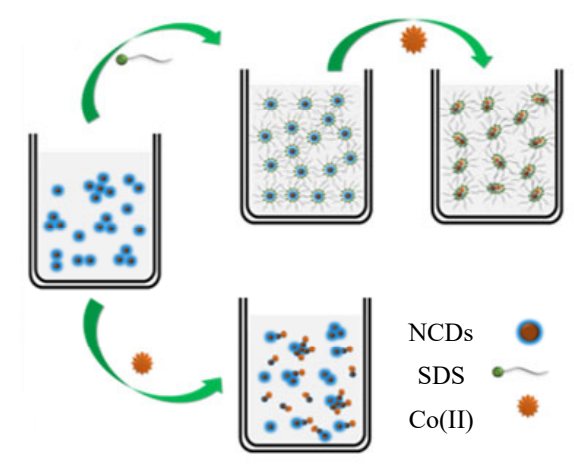

(b)

Fig. 10 Sensitization mechanism of SDS: (a) UV-Vis spectrum of different system and (b) schematic diagram of the mechanism of interaction between $\mathrm{Co}$ (II) and N-CD.

\section{Conclusions}

The nitrogen-doped carbon quantum dots $(\mathrm{N}-$ CDs) was synthesized by the microwave method, and the fluorescence quenching value of $\mathrm{Co}$ (II) quenched N-CDs effectively increased after SDS sensitization. A novel method of $\mathrm{Co}$ (II) determination based on SDS sensitization fluorescence quenching effect of nitrogen-doped carbon quantum dots was established. Finally, this method has been applied for the determination of $\mathrm{Co}(\mathrm{II})$ in real samples with satisfactory results. 


\section{Acknowledgment}

The authors acknowledge Yangzhou University and funding projects. This paper is funded by the National Natural Science Foundation of China (Grant No. 21375117) and the Priority Academic Program Development of Jiangsu Higher Education Institutions.

Open Access This article is distributed under the terms of the Creative Commons Attribution 4.0 International License (http://creativecommons.org/licenses/by/4.0/), which permits unrestricted use, distribution, and reproduction in any medium, provided you give appropriate credit to the original author(s) and the source, provide a link to the Creative Commons license, and indicate if changes were made.

\section{References}

[1] J. Anastassopoulou and T. Theophanides, "The role of metal ions in biological systems and medicine," Bioinorganic Chemistry, 1995, 459: 209-218.

[2] S. Liao, F. Zhu, X. Zhao, H Yang, and X. Chen, "A reusable $\mathrm{P}, \mathrm{N}$-doped carbon quantum dot fluorescent sensor for cobalt ion," Sensors and Actuators BChemical, 2018, 260: 156-164.

[3] V. Mudgal, N. Madaan, A. Mudgal, R. Singh, and S. Mishra, "Effect of toxic metals on human health," Open Nutraceuticals Journal, 2010, 3(1): 94-99.

[4] A. Khorrami, T. Hashempur, A. Mahmoudi, and A. Karimi, "Determination of ultra trace amounts of cobalt and nickel in water samples by inductively coupled plasma-optical emission spectrometry after preconcentration on modified $\mathrm{C}_{18}$-silica extraction disks," Microchemical Journal, 2006, 84(1-2): 7579.

[5] A. Uzun Karatepe, M. Soylak, and L. Elci, "Cobalt determination in natural water and table salt samples by flame atomic absorption spectroscopy/on-line solid phase extraction combination," Analytical Letters, 2002, 35(14): 2363-2374.

[6] M. Saqib, L. Qi, P. Hui, A. Nsabimana, M. Halawa, W. Zhang, G. Xu, "Development of luminol-Nhydroxyphthalimide chemiluminescence system for highly selective and sensitive detection of superoxide dismutase, uric acid and $\mathrm{Co}^{2+}$," Biosensors and Bioelectronics, 2017, 99: 519-524.

[7] O. Xu, S. Wan, Y. Zhang, J. Li, and X. Zhu, "A unique dual-excitation carbon quantum dots: Facile synthesis and application as a dual-'on-off-on' fluorescent probe," Sensors and Actuators B: Chemical, 2021, 340: 129904.

[8] S. Liu, J. Cui, J. Huang, B. Tian, F. Jia, and Z. Wang,
"Facile one-pot synthesis of highly fluorescent nitrogen-doped carbon dots by mild hydrothermal method and their applications in detection of $\mathrm{Cr}(\mathrm{VI})$ ions," Spectrochimica Acta Part a-Molecular and Biomolecular Spectroscopy, 2019, 206: 65-71.

[9] X. Xu, R. Ray, Y. Gu, H. Ploehn, L. Gearheart, K. Raker, et al., "Electrophoretic analysis and purification of fluorescent single-walled carbon nanotube fragments," Journal of the American Chemical Society, 2004, 126(40): 12736-12737.

[10] U. Kamran, Y. Heo, J. Lee, and S. Park, "Functionalized carbon materials for electronic devices: a review," Micromachines, 2019, 10(4): 234.

[11] Y. Zhang, H. Qin, Y. Huang, F. Zhang, H. Li, H. Liu, et al., "Highly fluorescent nitrogen and boron doped carbon quantum dots for selective and sensitive detection of $\mathrm{Fe}^{3+}$," Journal of Materials Chemistry B, 2021, 9: 4654-4662.

[12] D. Dang, S. Chandrasekaran, Y. Ngo, J. Chung, E. Kim, and S. Hur, "One pot solid-state synthesis of highly fluorescent $\mathrm{N}$ and $\mathrm{S}$ co-doped carbon dots and its use as fluorescent probe for $\mathrm{Ag}^{+}$detection in aqueous solution," Sensors and Actuators BChemical, 2018, 255: 3284-3291.

[13] S. Park, T. Kim, and Y. Jung, "Glutathione-decorated fluorescent carbon quantum dots for sensitive and selective detection of levodopa," Analytica Chimica Acta, 2021, 1165: 338513.

[14] X. Sun and Y. Lei, "Fluorescent carbon dots and their sensing applications," Trac-Trends in Analytical Chemistry, 2017, 89: 163-180.

[15] L. Shi, X. Li, Y. Li, X. Wen, J. Li, M. Choi, et al., "Naked oats-derived dual-emission carbon nanodots for ratiometric sensing and cellular imaging," Sensors and Actuators B: Chemical, 2015, 210: 533541.

[16] U. Kamran, K. Rhee, and S. Park, "Effect of triblock copolymer on carbon-based boron nitride whiskers for efficient $\mathrm{CO}_{2}$ adsorption," Polymers, 2019, 11(5): 913.

[17] U. Kamran and S. Park, "Chemically modified carbonaceous adsorbents for enhanced $\mathrm{CO}_{2}$ capture: A review," Journal of Cleaner Production, 2021, 290(578): 125776.

[18] L. Bu, T. Luo, H. Peng, L. Li, D. Long, J. Peng, et al., "One-step synthesis of $\mathrm{N}$-doped carbon dots, and their applications in curcumin sensing, fluorescent inks, and super-resolution nanoscopy," Microchimica Acta, 2019, 186(10): 675.

[19] S. Dsouza, M. Buerkle, P. Brunet, C. Maddi, and V. Svrcek, "The importance of surface states in Ndoped carbon quantum dots," Carbon, 2021, 183: 111.

[20] Y. Liu, Y. Liu, S. Park, Y. Zhang, T. Kim, S. Chae, et al., "One-step synthesis of robust nitrogen-doped carbon dots: acid-evoked fluorescence enhancement and their application in $\mathrm{Fe}^{3+}$ detection," Journal of 
Materials Chemistry A, 2015, 3(34): 17747-17754.

[21] A. Kumar, Y. Kuang, Z. Liang, and X. Sun, "Microwave chemistry, recent advancements, and eco-friendly microwave-assisted synthesis of nanoarchitectures and their applications: a review," Materials Today Nano, 2020, 11: 100076.

[22] Y. Liu, D. Guo, Y. Gao, N. Tong, Y. Li, and Y. Zhu, "Non-thermal effect of microwave on the chemical structure and luminescence properties of biomassderived carbon dots via hydrothermal method," Applied Surface Science, 2021, 522: 149503.

[23] I. Hoffmann, M. Theile, S. Gratz, J. Scholz, P. Barreleiro, W. Rybinski, et al., "On the influence of surfactants on the adsorption of polysaccharidebased polymers on cotton studied by means of fluorescence spectroscopy," Langmuir, 2012, 28(31): 11400-11409.

[24] Z. Wang, Z. Zhang, Z. Fu, Y. Xiong, and X. Zhang, "A flow-injection ultrafiltration sampling chemiluminescence system for on-line determination of drug-protein interaction," Analytical and Bioanalytical Chemistry, 2003, 377(4): 660-665.

[25] Q. Ren and X. Zhu, "Methyl-beta-cyclodextrin /cetyltrimethyl ammonium bromide synergistic sensitized fluorescence method for the determination of levofloxacin," Journal of Fluorescence, 2016, 26(2): 671-677.

[26] Q. Yang, C. Yan, and X. Zhu, "A fluorescent chemosensor for paeonol based on tetramethoxy resorcinarene tetraoxyacetic acid," Sensors and Actuators B: Chemical, 2014, 191: 53-59.

[27] G. He, M. Shu, Z. Yang, Y. Ma, D. Huang, and $\mathrm{S}$. $\mathrm{Xu}, \quad$ "Microwave formation and photoluminescence mechanisms of multi-states nitrogen doped carbon dots," Applied Surface Science, 2017, 422: 257-265.

[28] H. Sutanto, I. Alkian, N. Romanda, I. Lewa, and P. Triadyaksa, "High green-emission carbon dots and its optical properties: microwave power effect," AIP Advances, 2020, 10(5): 055008.

[29] X. Liu, C. Yang, B. Zheng, J. Dai, L. Yan, Z. Zhuang, et al., "Green anhydrous synthesis of hydrophilic carbon dots on large-scale and their application for broad fluorescent $\mathrm{pH}$ sensing," Sensors and Actuators B: Chemical, 2018, 255: 572-579.

[30] S. Choudhury, J. Chethodil, P. Gharat, P. Praseetha, and $\mathrm{H} . \mathrm{Pal}$, "pH-elicited luminescence functionalities of carbon dots: mechanistic insights," Journal of Physical Chemistry Letters, 2017, 8(7): 1389-1395.

[31] F. Yan, Z. Bai, F. Zu, Y. Zhang, X. Sun, and T. Ma, "Yellow-emissive carbon dots with a large stokes shift are viable fluorescent probes for detection and cellular imaging of silver ions and glutathione," Microchimica Acta, 2019, 186(2): 113.

[32] Z. Wang, X. Xing, Y. Yang, R. Zhao, T. Zou, Z. Wang, Y. Wang, "One-step hydrothermal synthesis of thioglycolic acid capped CdS quantum dots as fluorescence determination of cobalt ion," Scientific Reports, 2018, 8: 8953.

[33] Y. Yao, D. Tian, and H. Li, "Cooperative binding of bifunctionalized and click-synthesized silver nanoparticles for colorimetric $\mathrm{Co}^{2+}$ sensing," $A C S$ Applied Materials \& Interfaces, 2010, 2(3): 684-690.

[34] C. Zhao, X. Lia, C. Cheng, and Y. Yang, "Green and microwave-assisted synthesis of carbon dots and application for visual detection of cobalt(II) ions and pH sensing," Microchemical Journal, 2019, 147: 183-190.

[35] B. Hemmateenejad, M. Shamsipur, F. Samari, and H. Rajabi, "Study of the interaction between human serum albumin and Mn-doped $\mathrm{ZnS}$ quantum dots," Journal of the Iranian Chemical Society, 2015, 12(10): 1729-1738.

[36] L. Ma and X. Zhu, "Determination of emodin by hexadecyl trimethyl ammonium bromide sensitized fluorescence quenching method of the derivatives of calix[4]arene," Spectrochimica Acta Part A Molecular \& Biomolecular Spectroscopy, 2012, 95: 246-251.

[37] N. Correa, J. Silber, R. Riter, and N. Levinger, "Nonaqueous polar solvents in reverse micelle systems," Chemical Reviews, 2012, 112(8): 45694602. 